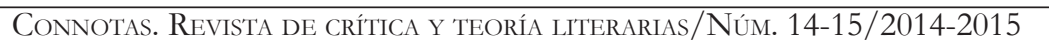

\title{
Influencias platónicas en la cuentística arreolina
}

\author{
Iram Isaí EvangELISTA ÁvILA* \\ Erbey Mendoza Negrete*
}

\begin{abstract}
Resumen:
Como parte de su creación literaria, Juan José Arreola utiliza ciertas referencias platónicas que matizan su prosa cuentística. En el siguiente trabajo ensayístico, se discurre entre tres de estos elementos: la visión de la pareja como Andrógino, el amor como una identidad daimónica y la dialéctica literaria. El análisis explicativo e interpretativo van guiados a través del método analógico, a saber: intra e intertextualidad, semántica (a la manera de Ricœur y Beuchot) y pragmática.
\end{abstract}

\section{Palabras clave:}

Cuento, andrógino, daimon, dialéctica literaria.

En la cuentística de Juan José Arreola subyacen ciertos rasgos del pensamiento del autor que, al descubrirlos, nos dan la pauta para elaborar otro tipo de acercamiento y llegar a un nuevo horizonte. Este recurso fortalece la narrativa de "El último juglar". El escritor utiliza la trama para dejarnos entrever su pensamiento, el cual, a través de la simbología utilizada, nos ubica por completo en el terreno de la interpretación literaria.

Arreola se sirve de la narración para desarrollar su visión particular del mundo y, de esta manera, el autor no solamente entrega

\footnotetext{
* Universidad Autónoma de Chihuahua.
} 
al lector relatos de ficción, sino que también pone a nuestra disposición un ideario personal. Esta cualidad del relato arreolino nos invita a proseguir con el diálogo literario. Para comprender ciertos aspectos de su cuentística hay que aproximarse a las influencias platónicas que el autor de Bestiario cobija en su visión del mundo. Expondremos lo anterior con tres elementos alojados en la obra del narrador: la pareja, el daimon y lo que se llamará dialéctica literaria. ${ }^{1}$

\section{La reminiscencia platónica en Arreola}

Dentro de la narrativa arreolina existen ciertas referencias y figuras discursivas análogas con respecto a las reflexiones platónicas. Se rescata una cita encontrada en La palabra educación, que nos guiará en adelante con el presente discurso:

La memoria hace que el espíritu, que el ser, responda a la situación presente con los recursos del pasado. Yo combino los datos del pasado y respondo, porque de todo guardo alguna reminiscencia. La famosa inteligencia es la capacidad de unir unas cosas con otras, de ligar hechos correspondientes. Hablo de Platón por medio de veinte o treinta autores que me han ayudado a comprender la grandeza platónica. Me importa Platón, aunque no lo haya leído personalmente y a fondo, porque yo soy platónico (104). ${ }^{2}$

${ }^{1}$ A partir de aquí el sustantivo daimon aparecerá sin cursivas para agilizar la lectura.

${ }^{2}$ Para evitar algún equívoco en cuanto al conocimiento de la obra de Platón por parte del narrador, siento necesario hacer la siguiente aclaración. En una charla sostenida con Orso Arreola, él mismo corrobora el conocimiento del filósofo por parte de Juan José Arreola: "Por supuesto que Arreola leyó y conoció a Platón. En su biblioteca tiene algunas ediciones de los Diálogos, puesto que él mismo decía ser platónico. No solamente en su narrativa, sino en ciertas actitudes de su quehacer diario". 
"El último juglar" señala que su pensamiento está influido por ciertas variables platónicas, pero deja en claro que no es un experto académico dentro de la filosofía platónica, sino que podemos mencionar que él "recobra" y que de cierta manera "vive" y comulga con el pensamiento del filósofo. Cabe apuntar que la cita anterior dicha por Arreola obedece a cierto pasaje dentro de los Diálogos de Platón, quien a través del personaje de Sócrates menciona la forma en que se presenta cierto conocimiento (por así llamarlo), que viene del pasado y que funge como un tipo de inteligencia. También hay que señalar que el proceso de reminiscencia consistía en hacer "recordar" lo que la persona había aprendido en una vida pasada por medio de ciertas preguntas, así el sujeto lograba "recobrar" lo adquirido antaño:

Saber no es más que recordar, y el recuerdo supone un conocimiento anterior; por consiguiente, si el alma se acuerda de cosas que no ha podido conocer en esta vida, es una prueba de que ha existido ántes. ¿No es cierto que nuestra alma, al través de la imperfecta igualdad que muestran los objetos sensibles entre sí, tiene la idea de una igualdad perfecta, inteligible é inaccesible á los sentidos? ¿No tiene asimismo la idea del bien, de lo justo, de lo santo y de la esencia de todas las cosas? Estos conocimientos no ha podido adquirirlos después de nacer, puesto que no son perceptibles á los sentidos, y es preciso que los haya adquirido ántes: "la consecuencia de todo es que el alma existe ántes de nuestra aparicion [sic] en este mundo, y lo mismo las esencias" (Azcárate 5: 12).

\subsection{El contexto arreolino de la pareja y el influjo platónico}

En primera instancia se desarrollará el contexto arreolino de la pareja. Es sabido que en la mayoría de los cuentos el autor jalisciense muestra el conflicto de la relación del hombre con la mujer. Es difícil encontrar la armonía de la pareja dentro de la trama; más bien lo inarmónico sobresale en los personajes. Existe una pasión, pero una que lleva a la aniquilación del otro. Dentro del cuento 
"La trampa", podemos encontrar ciertos parámetros que ayudarán a revisar esta situación. La voz de quien narra el acontecimiento nos describe la situación tensa que le provoca la mujer: "Cada vez que una mujer se acerca turbada y definitiva, mi cuerpo se estremece de gozo y mi alma se magnifica de horror" (Narrativa completa 124). ${ }^{3}$ Desde un inicio la trama nos dispone un duelo entre ambas figuras; la mujer como víctima y victimizante, y la presencia masculina como receptor y víctima. La narración prosigue con semejante matiz: "La veo abrirse y cerrarse. Rosas inermes o flores carniceras, en sus pétalos funcionan goznes de captura: párpados tiernos, suavemente aceitados de narcótico" (124). Las referencias destructivas protagonizadas por esta insana relación obedecen a un conflicto de reintegración, de consumo o engullimiento. Pudiera mencionarse que son fruto del odio, pero de un odio basado en el amor, en el deseo de pertenencia de la pareja. Una codependencia que tiene su cúspide en la absorción de la persona. No obstante, esta situación destructiva del otro puede ser tratada como una reacción de complementariedad, de volver a ser uno; más allá de postulados simplistas de carácter misógino, la propuesta que nos aparece en los relatos a analizar obedece a un plano con mayor profundidad.

"Oh Maldita, acoge para siempre el grito del espíritu fugaz, en el pozo de tu carne silenciosa" (124). En esta última línea recibimos con mayor asertividad la voz del amante abrumado. Es en este momento donde podemos analizar dos diferentes, pero a la vez unidas situaciones. La primera es la evocación del parto y que en el autor es de vital importancia: "Venero y odio a la mujer. La veo siempre en equilibrio inestable. Ella es el verdadero ser, el ser original, la criatura total que nos llevaba dentro. Creo que en la división del parto original, a la mujer se le escapó el espíritu" (Arreola, Y ahora,

\footnotetext{
${ }^{3}$ En Y abora, la mujer se lee: "Cuando una mujer se acerca a darme el ensueño, además me acarrea la pesadilla. Ella me trae las semillas del amor y los gérmenes de la muerte" (12). Esta sentencia que el propio autor menciona en este libro (que es una recopilación de charlas de Arreola), obedece a una mímesis analógica, la cual recrea el pensamiento del autor y la plasma en su narrativa.
} 
la mijer 17). Al mismo tiempo, el autor nos muestra, en sus propias palabras, lo siguiente: "Quien estudie mi obra debe verificar literariamente, porque para mí es fundamental, la imagen del parto" (Carballo, Diecinueve 380).

Empero, la figura del parto es una de dos cualidades recurrentes en la cuentística del narrador. También encontramos la figura de la pareja como un solo ser arrancado por el sino. Así, el autor representa esta unión y desunión de la pareja de la siguiente manera: "cada vez que el hombre y la mujer intentan construir el arquetipo, componen una criatura monstruosa, que es la pareja" (Beneyto 271). Al unirse el hombre y la mujer, crean un ser único que recuerda al "andrógino" que se menciona en el diálogo del "Banquete", donde, por igual, se discurre lo que es el amor. No obstante, en la separación nace el conflicto, se transforma en esa entidad grotesca que se manifiesta en la pareja sentenciada a vivir junta: "la pareja es un molino prehistórico en el que dos piedras ruejas se muelen a sí mismas interminablemente, hasta la muerte" (Gómez 251).

Dentro de los Diálogos de Platón, se explica este ser al cual se hace referencia y del cual se originan los sexos de la raza humana: el andrógino. La entidad mencionada era un ser completo y bisexuado, en el cual la humanidad encerraba su plenitud. Empero, su orgullo y su vanidad lo llevaron a desafiar a los dioses. Zeus lo castiga partiéndolo en dos; de una mitad nació el sexo femenino y de la otra mitad el masculino. Hombre y mujer están condenados a buscar a su otro para lograr formar de nuevo la plenitud sentenciada, como se explica en el "El banquete" (Platón 222-29).

Juan José Arreola utiliza a este personaje mitológico para simbolizar la pugna entre los personajes de su narrativa. Es debido a esta separación o división del ser que se desemboca en la lucha cruenta entre sus antagonistas. Femenino y masculino se rebelan entre sí para absorberse y completarse, para apropiarse de su pareja y recobrar la plenitud. La desunión, la individualidad, permite que el personaje vague y que la libertad sea el motivo del conflicto. Mientras uno de ellos sea libre, el otro sufre, odia y anhela la complementariedad, cuya acción solamente llegará en el aniquilamiento, en el apropiamiento que dará como resultado la prevalencia del "uno". 
Dentro de este drama de la escisión de los géneros encontramos el cuento "Eva", que pertenece al libro Confabulario. Al terminar la lectura del cuento, podemos deducir que su título y su discurso representan al género femenino histórico. La protagonista enfrenta al hombre y reclama sus derechos: "infinitamente violados. Durante cinco mil años ella había sido inexorablemente vejada, postergada, reducida a la esclavitud" (88). Los argumentos del personaje femenino son rebatidos por el eterno enamorado; empero, por más intentos de este: "a la muchacha todas estas cosas la dejaban fría" (88). La acción se desarrolla en una biblioteca, un lugar neutral debido a que ahí se aloja el pensamiento universal de la humanidad. Es hasta que el joven recuerda y cita a Heinz Wölpe, que logra acceder a la mujer:

En el principio sólo había un sexo, evidentemente femenino, que se reproducía automáticamente. Un ser mediocre comenzó a surgir en forma esporádica, llevando una vida precaria y estéril frente a la maternidad formidable. Sin embargo, poco a poco fue apropiándose ciertos organismos esenciales. Hubo un momento en que se hizo imprescindible. La mujer se dio cuenta, demasiado tarde, de que le faltaban ya la mitad de sus elementos y tuvo la necesidad de buscarlos en el hombre, que fue hombre en virtud de esa separación progresista y de ese regreso accidental a su punto de origen. La tesis de Wölpe sedujo a la muchacha. Miró al joven con ternura "El hombre es un hijo que se ha portado mal con su madre a través de la historia", dijo casi con lágrimas en los ojos (89).

Lo anterior comulga con el pensamiento arreolino de la pareja y estrecha la analogía platónica del ser primigenio. En esta instancia incluso podemos acercarnos a ambas situaciones: parto y androginia. El ser andrógino (con carácter femenino) "da a luz" a un ente (masculino), el cual es la "mitad" del original. De esta manera, el discurso del conflicto, sea parto o mitológico, trata de explicar el arrebato, el ansia de recobrar al "único". Dentro de la trama cuentística, la pugna entre géneros es el asalto por la totalidad original. La armonía existió 
durante la condición andrógina o preparto; la inarmonía, en cambio, nace en el momento mismo de la separación. El arranque se convierte en incomprensión, miedo, odio.

$\mathrm{Al}$ volver con la intriga de los protagonistas ¿la pareja en la cuentística arreolina se ama? Otra característica de esta situación andrógina-preparto, es que existe un amor apasionado entre una o las dos partes. El amor en el discurso platónico y en el resto del género humano se basta con ser unilateral.

Podemos encontrar a través de las explicaciones dadas que la pasión trágica entre hombre y mujer añora la situación andrógina o preparto; al encontrarse ante este imposible la lucha emerge entre los contrincantes como reclamo, incomprensión. ¿Por qué entonces nace la trama de la pareja? He de aventurarme a decir simplemente que es porque ninguno puede bastarse por sí mismo; la respuesta es platónica: hombre y mujer están destinados a buscar su otra parte arrebatada. El intento de conciliación por ambas partes, naturalmente diferentes, crea la inarmonía y el perjuicio. ${ }^{4}$ Juan José Arreola utiliza la figura humana para explicar un género que no tiene ni los elementos intelectuales ni biológicos para resistirse a la tentación de unirse con su verdugo. Este género, activo o pasivo, es incapaz de resistirse a su ideal amoroso, cae por igual en el deseo, el ser poseído o apoderado: la meta inalcanzable de comprenderse en la unidad. ${ }^{5}$

\footnotetext{
${ }^{4}$ En los personajes, el ejercicio de la libertad se gana haciendo un ejercicio de poder, esta situación se dirige en el sometimiento de la otra figura.

${ }^{5}$ Algunos autores, como Antonio Gómez Robledo, mencionan que si Aristófanes es quien explica el mito del Andrógino dicho mito puede ser reducido a una burla debido a que: "De lo que se necesita en esos momentos, y en un banquete sobre todo, es de un hazmerreír, y en ese terreno Aristófanes no tenía entonces rival, ni lo tuvo, a lo que nos parece, hasta Molière" (393). Aunque fuera cierta esta aseveración y el mito del Andrógino fuera burla y no parte de la creencia popular, la pareja en Arreola sigue cumpliendo con la imagen simbólica debido a la búsqueda y al absurdo.
} 


\subsection{Amory daimon}

El amor que envuelve a la pareja arreolina cabe dentro de la exposición platónica, empero, existe un segundo elemento, pues no solamente puede explicarse a través del mito, sino que también comparte la característica daimónica. ${ }^{6}$ La participación del daimon, para justificación de este diálogo, se tomará como representante del amor.

En "El banquete" un joven Sócrates es aleccionado por Diotima. La filósofa le explica que el amor es un gran demonio o daimon, el cual fue engendrado en la celebración por el nacimiento de Afrodita. Los padres de este daimon, cuyo nombre es Eros, son Poros (sagacidad) y Penía (la carencia, la pena). Aparte de esto, Diotima explica las características heredadas por Eros:

En primer lugar, es siempre pobre, y lejos de ser delicado y bello, como cree la mayoría, es, más bien, duro y seco, descalzo y sin casa, duerme siempre en el suelo y descubierto, se acuesta a la intemperie en las puertas y al borde de los caminos, compañero siempre inseparable de la indigencia por tener la naturaleza de su madre. Pero, por otra parte, de acuerdo con la naturaleza de su padre, está al acecho de lo bello y de lo bueno; es valiente, audaz y activo, hábil cazador, siempre urdiendo alguna trama, ávido de sabiduría y rico en recursos, un amante del conocimiento a lo largo de toda su vida, un formidable mago, hechicero y sofista (Platón 246-49).

Si seguimos con la raíz platónica, el amor es proactivo al desequilibrio, un estado intermedio entre lo bochornoso y la temeridad. Esta situación dual corre entre lo execrable y lo sublime. La búsqueda y el encuentro de estos aspectos del Eros, son figuras irrevocables en la narrativa de Juan José Arreola. No podemos ne-

\footnotetext{
"Anteriormente he trabajado la figura daimónica como "consejera" (Cf. Evangelista). Para lograr mayor unidad, en el presente discurso se trata como rasgo del amor.
} 
gar la analogía existente entre el desenvolvimiento arreolino de la pareja y la exposición del Eros platónico; la desaventura del amor logra reproducirse en el cuento. En un inicio alterno se puede suponer el amor idílico, un plano donde ese amor logró alguna estabilidad armónica, ya fuera entre ambas partes o en sentido unilateral: pero en ese momento no existe trama, esta se desarrolla en su segunda fase de desequilibrio (expulsión o separación). El clímax se muestra dentro del sufrimiento del personaje, ahí es donde existe la narrativa, el momento de la literatura.

En ambas apariciones daimónicas, la arreolina y la platónica, la entidad tiene el carisma de lo familiar, de lo diario; no es una situación extraña o algún rasgo del tipo deus ex maquina; tanto para la cuentística como para el diálogo filosófico, el daimon es algo que mueve las decisiones de sus receptores y que los guía a través de su camino, en este caso en particular la decisión de caer irremediablemente en el amor al otro.

\subsection{Dialéctica literaria}

El tercer y último elemento dentro de este análisis corresponde a lo que llamaremos: dialéctica literaria. Juan José Arreola no solamente fue un maestro de la creación narrativa, sino también un docente de literatura. Al revisar sobre su propuesta educativa, Arreola se preocupa por mostrar lo que se puede aprender a través de la creación literaria, no solamente en aristas receptivas, sino como una forma de aprendizaje humanista que se da por medio del diálogo autor-texto-lector: "El propósito de un curso es introducir y aproximar, enseñar al alumno a conocer y a juzgar las obras del espíritu. Pero sobre todo a amarlas con amor consciente y nuevo, que es el único que puede darnos un conocimiento de ellas" (Arreola, La palabra educación 111). El maestro Arreola propone una actividad enseñanza-aprendizaje: al alumno se le muestra cómo puede acercarse a la literatura y cómo puede comenzar a elaborar juicios críticos a partir de ella. Propone un aprender a aprender a acercarse a la literatura y amarla. Con ello se apropia del conocimiento y de

la obra de arte literaria. La literatura se vuelve el objeto de estudio 
y esto se logra dentro del discurso activo de una dialéctica literaria: " "No es necesario el formulario por escrito, sino sencillamente preguntar: ¿Cuál fue el resultado pedagógico? Y más importante todavía preguntar: ¿Cuál fue su experiencia humana con respecto al instructor? ¿Cuáles los valores de comunicación, de afecto, de solidaridad, casi de fraternidad?" (131). El ejercicio y desarrollo socioafectivo en el aula y la convivencia entre alumno y maestro, son piedra angular para construir el aprendizaje, no solamente de la literatura, sino del conocimiento en general: "El maestro debe comunicar su personal deleite de lector, ilustrar el estudio con metáforas, hacer del curso mismo una obra literaria llena de animación y movimiento, de emoción y fantasía" (134). El aprendizaje significativo de la literatura mueve la intención docente de "El último juglar": el abordaje meramente lineal o normativo queda en el examen, pero el conocimiento verdadero de la obra literaria, la aprehensión del texto poiético, es lo fundamental y lo constructivo para edificar el acervo cognoscitivo del lector.

Esta situación dialéctica maestro-alumno, de acción y recepción, creo que es un fin que se puede trasladar al de autor-obra-lector. Como se ha discurrido en este y otros ensayos, el pensamiento de Juan José Arreola se encuentra mimetizado en su obra literaria, y es muy probable que el maestro llevase esta idea del diálogo a su universo narrativo. ${ }^{8} \mathrm{El}$ cuento arreolino busca el diálogo con el lector, pero creo que en su papel de maestro también desea enseñar algo al lector, algo del acto de leer.

Un fabulista como Juan José Arreola propone el discurso con el lector mediante el desenvolvimiento del texto; Arreola desea transmitir su mensaje, su propuesta de diálogo a través de la narración. Un gran fabulista que goza contando historias, o incluso inventándolas. ¿Se tratará más bien de un método didáctico para explicar

\footnotetext{
${ }^{7}$ Los términos "enseñanza-aprendizaje”, "aprendizaje significativo" y "aprender a aprender" los retomo del enfoque constructivista de la educación y del Informe Delors.

${ }^{8}$ Mímesis, como la define y maneja Paul Ricœur.
} 
ideas abstractas mediante metáforas e imágenes gráficas? ¿Será acaso que el cuento arreolino también muestra rasgos de enseñanza hacia el acto de leer?

Para ello, creo que algunos de sus cuentos siguen una trayectoria de dialéctica literaria. Así también comulga con la idea platónica de aprendizaje a través del cuestionamiento. Ahora, este diálogo puede llevarse a cabo a través de la recepción literaria y, más concretamente, como Hans Robert Jauss la explica, por medio de poiesis, aisthesis, y catarsis, ${ }^{9}$ o bien, buscar fines interpretativos análogos como es la hermenéutica literaria.

Esta comunión, que el autor propone por medio de su obra, busca atrapar al lector como: "una hormiga león, si son las hormigas león las que hacen un embudo en la arena para que sus víctimas resbalen al fondo. Cuatro palabras y zas, adentro" (El último juglar 289); donde se lleve la literatura a otro horizonte, contextuarla y enriquecerla precisamente por medio del diálogo vivo, activo.

En Arreola, el lector debe preguntarse sobre lo que determinados cuentos brindan en cuanto a su propia recepción y aprendizaje de la obra literaria. Lo anterior transita en rangos de interpretación y enseñanza-aprendizaje, pues toda enseñanza y aprendizaje por naturaleza ejercen una interpretación. Las siguientes preguntas ayudan a la argumentación del proceso lector: “¿qué significa este

\footnotetext{
${ }^{9}$ Con respecto a esto, Jauss menciona: "La función catártica no es la única transmisora de la capacidad comunicativa de la experiencia estética: también la transmite la aisthesis, cuando el observador, en un acto contemplativo que renueva su percepción, capta lo percibido como una comunicación del mundo ajeno, o cuando, en el juicio estético, aprehende una norma de conducta. Por otra parte, la actividad aisthética puede convertirse en poiesis: el observador puede considerar un objeto estético como imperfecto, abandonar su postura contemplativa y convertirse en co-creador de la obra, con lo que perfecciona la concretización de su figura y su significación. Por último, la experiencia estética puede incluirse en el proceso de formación estética de la identidad: así, cuando el lector acompaña su actividad aisthética con la reflexión sobre su propio devenir 'por mucho que se diga, la validez del texto no procede de la autoridad de su autor, sino de la confrontación con nuestra historia vital, de la que nosotros somos autores, pues cada uno es autor de la historia de su vida' (Zimmermann)" (77-78).
} 
texto?, ¿qué quiere decir?, ¿a quién está dirigido?, ¿qué me dice a mí?, o ¿qué dice ahora?, y otras más (Beuchot, 28). O que pueden ir en un rumbo paralelo: "¿cómo funciona el texto?, ¿de qué habla el texto?, ¿qué me dice el texto?, ¿cómo he leído el texto?” (Casar 148). Estas y otras preguntas auxilian al momento de entablar el diálogo autor-obra-obra-lector; con ello se pueden alcanzar las siguientes metas: aprehender y comprehender el relato, y llegar a un autoconocimiento del lector. Las respuestas nos enseñan a valorar de mejor manera la charla cuentística pues encontramos una interiorización al relato por medio de nuestra propia interiorización: nosotros mismos somos un repertorio de vivencias que nos ayudarán a abrazar las intenciones arreolinas:

La literatura nos ofrece la oportunidad de ensayar un procedimiento nuevo y antiquísimo, que tal vez pueda influir en los métodos generales de la transición del saber. Me refiero a la restauración, a la reanudación del diálogo verdadero entre el que trata de aprender y el que se propone alentar esa voluntad de conocimiento. Aquí es inevitable recordar al maestro callejero, ilustre por su vida y por su muerte, que hacía crecer sus pensamientos en las mentes ajenas, mediante las provocaciones de una dialéctica útil. En vez de implantar autoritariamente un conocimiento, le gustaba verlo surgir en su interlocutor, casi espontáneamente, porque el mismo no estaba seguro de la bondad de la semilla que había dejado caer en el surco, sino cuando la veía florecer en bellos y ajenos pensamientos (La palabra educación 141).

En esta etapa de alumbramiento, de reconocimiento, es donde podemos alcanzar el diálogo franco con el objeto; aprehendemos y comprehendemos, logramos la obra de arte literaria: "El momento en que la literatura alcanza su eficiencia más alta es quizá aquel en que coloca al lector en la situación de recibir una solución para la que debe encontrar a su vez las preguntas apropiadas, aquellas que constituyen el problema estético y moral planteado por la obra" (Ricœur 3: 891). 
Hay que considerar que, por medio de esta dialéctica literaria, el lector, la obra y el propio autor alcanzan un objetivo ulterior, uno que logra "una toma de conciencia" de su valor y trascendencia; ${ }^{10}$ este sería un momento significativo, ya que se puede hablar de libertad en el pensamiento, toma de conciencia del contexto y realidad que se vive y que se puede obtener a través de la obra literaria en general. Se da la oportunidad "al otro" (el lector participativo), de hacer o llegar a sus propias revalorizaciones y conclusiones.

\section{Conclusiones}

En los cuentos aparecidos dentro de este ensayo, entre los reunidos en las diferentes compilaciones, Juan José Arreola promueve la intervención del receptor como participante en sus obras. La palabra dialogada emerge entre los intereses del narrador y la disemina en el relato para quien desee involucrarse en el ejercicio refigurativo de la lectura: "Como Sócrates con Alcibiades y con Platón por testigo: 'Al conversar tú y yo, intercambiando pensamientos, son las almas las que conversan'. Basta poner el alma en la conversación. Esto es lo que debe hacer un maestro cuando dialoga con sus alumnos" (Arreola, La palabra educación 142).

La forma en que el discurso arreolino se desenvuelve en parte de su creación narrativa se aproxima al pensamiento platónico. Ya sea mediante la relación entre el hombre y la mujer, la propuesta del amor como agente bivalente o la dialéctica literaria, el escritor se apoya en esta influencia para moldear la trama, crear el cuento y construir el diálogo literario.

${ }^{10}$ Como lo maneja la pedagogía crítica de Paulo Freire. 


\section{Obras consultadas}

Arreola, Juan José. Confabulario definitivo. $5^{\text {a }}$. ed. Ed. Carmen de Mora. Madrid: Cátedra, 2006.

—. La palabra educación. México: CONACULTA, 2002.

- Narrativa completa. México: Alfaguara, 2003.

- Y ahora, la mujer. México: CONACULTA, 2002.

Arreola, Orso. El último juglar: memorias de Juan José Arreola. Guadalajara: Jus, 2010.

Azcárate, Patricio de, trad. Obras completas de Platón. 11 vols. Madrid: Medina y Navarro editores, 1871. PDF.

Beneyto, María. "Confieso que aprendo mucho riéndome”. Rodríguez 266-277.

Beuchot, Mauricio. Tratado de hermenéutica analógica: hacia un nuevo modelo de interpretación. 4a. ed. México: UNAM, 2009.

Carballo, Emmanuel. Diecinueve protagonistas de la literatura mexicana del siglo veinte. México: Empresas editoriales, 1965.

Casar, Eduardo. Para qué sirve Paul Riccur en crítica y creación literarias. México: Universidad Iberoamericana, 2011.

Evangelista Ávila, Iram Isaí. "Aproximaciones a dos cuentos de Juan José Arreola a través de la hermenéutica analógica". Hermes analógica 5. (2014): 17-33. PDF.

Gómez Haro, Germaine. "Soy un desollado vivo”. Rodríguez 247-254. Gómez Robledo, Antonio. Platón: los seis grandes temas de su filosofía. México: FCE, 1982

Jauss, Hans Robert. "El placer estético y las experiencias básicas de la Poiesis, la Aisthesis y la catarsis". Experiencia estética y hermenéutica literaria. Madrid: Taurus, 1986.

Platón. Diálogos. Madrid: Gredos, 1988.

Ricœur, Paul. Tiempo y narración. 3 vols. México: Siglo XXI, 2009.

Rodríguez, Efrén, comp. Arreola en voz alta. México: CONACUlTA, 2002. 